\title{
INCLUSIVE EMPLOYMENT FOR PEOPLE WITH DISABILITY: A REVIEW
}

\author{
Marcos Gómez-Puerta ${ }^{1}$, Esther Chiner ${ }^{2}, \&$ María-Cristina Cardona-Moltó ${ }^{2}$ \\ ${ }^{1}$ Department of Developmental Psychology and Teaching, University of Alicante (Spain) \\ ${ }^{2}$ Department of Health Psychology, University of Alicante (Spain)
}

\begin{abstract}
Various organizations and institutions have supported in recent years the importance of achieving an improvement in the participation in society of people with disabilities through their access to employment. Despite the development of international conventions and specific action plans, people with disabilities continue to encounter barriers to their labour inclusion. The present study aimed to examine scientific production in the field of inclusive employment of people with disabilities from a bibliometric perspective. The sample of 127 documents on this subject was obtained from the core collection of Web of Science (WoS). Data analysis was performed using the bibliometric analysis tools available in WoS. The results indicate a progressive increase in the number of publications. However, the studies are still insufficient in order to be able to include an exhaustive knowledge of the conditions that make it difficult for these people to access employment, due to the wide range of types of disability and the variability of the characteristics of the people who present it. This being a preliminary study, it is advisable to continue with the bibliometric analysis of the data in order to achieve a better perspective of what has been published so far.
\end{abstract}

Keywords: Disability, employment, inclusive workplace, bibliometrics, barriers.

\section{Introduction}

The social model of disability (Oliver, 1983) considers that disability is a consequence of existing barriers in the subject's environment. These are manifested in access barriers, attitudes and behaviours that favour the discrimination of people whose capacities do not allow them to overcome such barriers. This approach is still in force today (Oliver, 2013), highlighting the need to identify and intervene in the barriers that limit the full participation in society of people with disabilities.

Based on the review by Khayatzadeh-Mahani et al. (2019), the barriers that limit access to employment, especially in the case of people with intellectual and developmental disabilities, are attributable to both individual factors and environmental factors. Barriers related to the characteristics of the subject include relationship and social skills difficulties, verbal and non-verbal language disorders, and difficulties in accepting changes in routines. Environmental barriers usually derive from the characteristics of the company (e.g. type of business, company size, location), policy and making insufficient or inappropriate job adjustments, attitudes and prejudices of the business community, perceived costs of hiring of a person with a disability, or low family expectations. Beyond social barriers, the systematic review conducted by Cheng et al. (2018) has shown that the majority of research related to the labour inclusion of people with disabilities has focused on individual-level strategies to provide employment support. Therefore, at present, there are still very few studies focused on determining the contextual factors that can improve the labour insertion of people with disabilities (Rey Pérez and Mateo Sanz, 2018). The reviews carried out so far on this topic have consisted of narrative reviews of the literature (Ruhindwa, Randall, and Cartmel, 2016; Shore, Cleveland, and Sanchez, 2018) but a general bibliometric analysis has not been shown, a deficiency that this study tries to compensate.

\section{Methods}

The purpose of this study was to examine the academic production on inclusive employment for people with disabilities in order to establish a preliminary overview of this area of study. This was done using a bibliometric methodology and a quantitative approach analysis to describe the evolution of research production, and productivity according to sources, authors, countries and affiliations. 


\subsection{Data collection}

To obtain a report on the scientific production of inclusive work environments, one of the most academically relevant databases was accessed on March 12, 2021: the core collection of the Web of Science (WoS). The key terms used for the search were "inclusive employment" and "disabilit*". The asterisk used in the term disabilit * served to give valid forms of the word in singular (disability) and plural (disabilities). The Boolean AND connector was used to select those documents that included both terms (inclusive employment AND disability / ies). The search allowed locating these terms both in the title, the keywords and abstract of the document. There were no restrictions on time period or language. In order to refine the data, a series of criteria were applied. In the first place, only documents belonging to the field of Social Sciences were chosen. Second, only the publications belonging to the WoS core collection were selected. Finally, those records that did not specifically refer to people with disabilities or that did not specifically address the field of inclusive employment were eliminated, as reflected in the following flow diagram.

Figure 1. Data collection and filtering flow diagram.

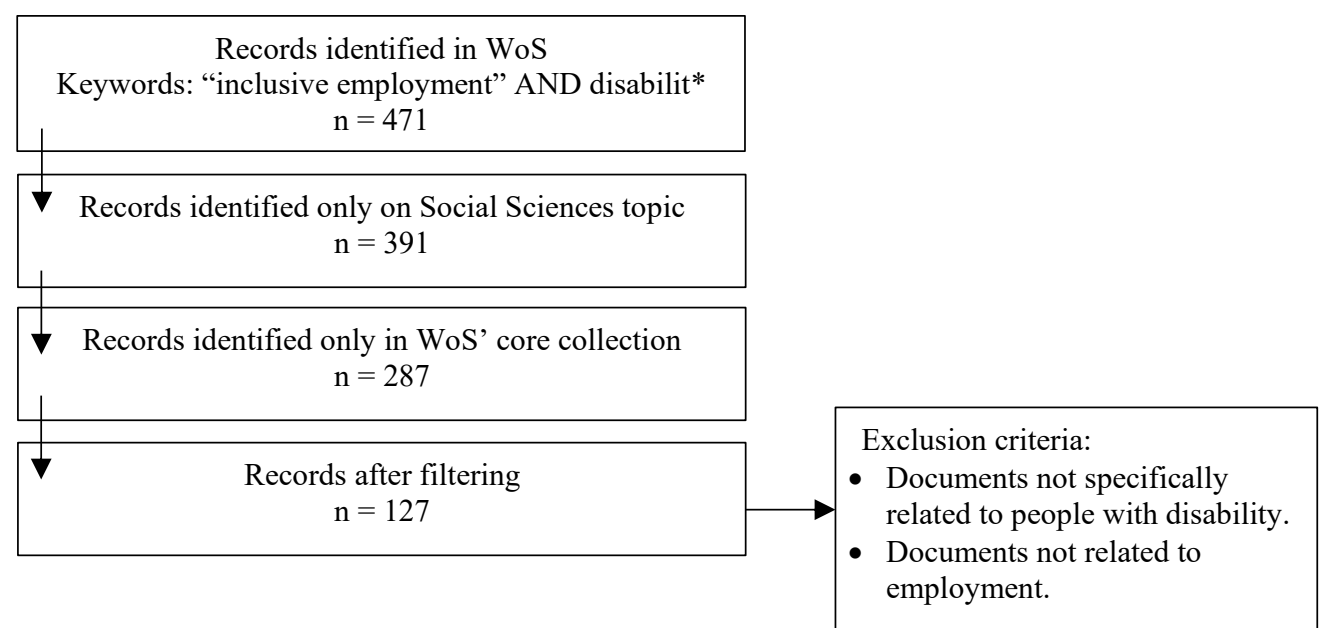

\subsection{Data analysis}

Once the data was compiled, these were analysed using the bibliometric analysis tools available in WoS. Consistent with the objectives of the study, production was described by year, by source, by author, and impact by country, institution, source, author, and document. The 127 documents corresponded to 101 articles $(79.5 \%), 13$ reviews (10.2\%), 7 conference papers $(5.5 \%)$ and 5 books $(4 \%)$ and other sources $(0.8 \%)$. Most of the documents were written in English $(n=118 / 92.9 \%)$.

\section{Results}

The results are presented in subsections according to the order of planned research objectives: scientific production, production by sources, production by the authors, and production by country and affiliation.

\subsection{Evolution of the scientific production by year}

The production ranges from 1990 to the present, 2021, as can be seen in the data reflected in figure 2. However, the publications have not had regularity over the years. For example, from 1991 to 1998 or from 2000 to 2003 there were no publications on the matter. Despite this, production has progressively increased, reaching the zenith so far in 2020 with 25 articles (19.6\% of the total in a single year). 
Figure 2. Annual scientific production on inclusive employment.

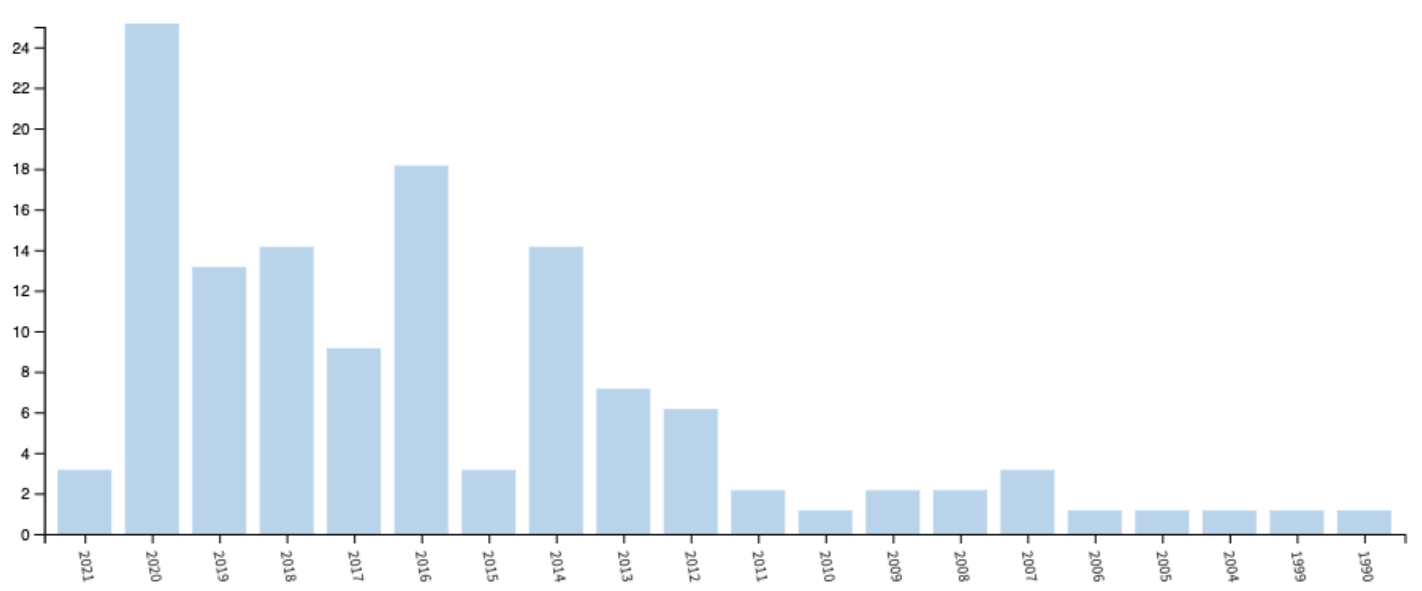

\subsection{Sources' productivity}

The most relevant sources in terms of the number of publications on the subject analysed are Disability \& Society $(n=11)$ and Work: A Journal of Prevention Assessment Rehabilitation $(n=7)$, as reflected in Table 1.

Table 1. Main Source Productivity.

\begin{tabular}{lc}
\hline Sources & Documents \\
\hline Disability \& Society & 11 \\
\hline Work: A Journal of Prevention Assessment Rehabilitation & 7 \\
\hline Disability and Rehabilitation & 5 \\
\hline International Journal of Environmental Research and Public Health & 4 \\
\hline International Journal of Human Resource Management & 3 \\
\hline Journal of Intellectual Developmental Disability & 3 \\
\hline Journal of Occupational Rehabilitation & 3 \\
\hline Personnel Review & 3 \\
\hline Canadian Journal of Nonprofit and Social Economy Research & 2 \\
\hline Equality, Diversity and Inclusion & 2 \\
\hline
\end{tabular}

\subsection{Authors' scientific production}

Regarding the production by authors, Ebuenyi and Reggeer are the most prolific in this field, having published three articles each. The rest of the authors among the 10 most productive have only published 2 articles (Figure 2).

Figure 2. Most relevant authors.

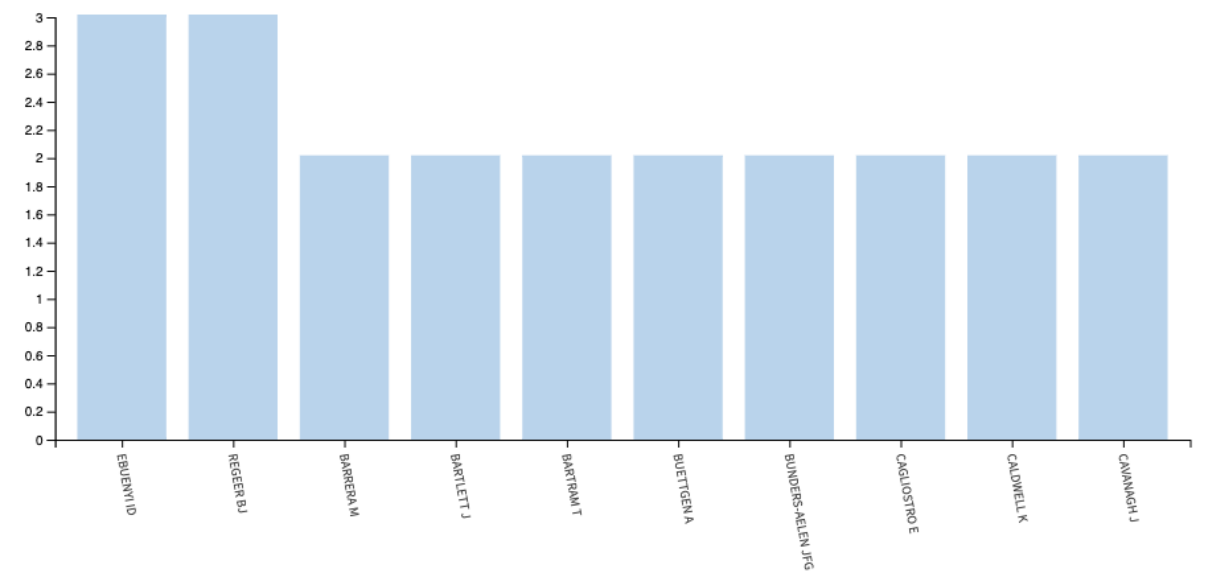

The 10 most relevant articles by the number of citations they have received since they were published are reflected in table 2 . 
Table 2. Most cited documents.

\begin{tabular}{|c|c|c|}
\hline Paper & TC & $\begin{array}{c}\text { TC per } \\
\text { year }\end{array}$ \\
\hline $\begin{array}{l}\text { Certo, N. J. et al. (2008). Seamless Transition and Long-Term Support for Individuals } \\
\text { With Severe Intellectual Disabilities. Research and Practice for Personas with Severe } \\
\text { Disabilities, 22(3), 85-95. }\end{array}$ & 46 & 3,29 \\
\hline Adamou, M. et al. (2013). Occupational issues of adults with ADHD. BMC Psychiatry, 13. & 36 & 4 \\
\hline $\begin{array}{l}\text { Lysaght, R., Cobigo, V. and Hamilton, K. (2012). Inclusion as a focus of employment- } \\
\text { related research in intellectual disability from } 2000 \text { to 2010: a scoping review- } \\
\text { Disability and Rehabilitation, 34(16), 1339-1350. }\end{array}$ & 36 & 3,4 \\
\hline $\begin{array}{l}\text { Lindsay, S., Cagliostro, E., Albarico, M., Mortaji, N., \& Karon, L. (2018). A Systematic } \\
\text { Review of the Benefits of Hiring People with Disabilities. Journal of Occupational } \\
\text { Rehabilitation, 28(4), 634-655. }\end{array}$ & 35 & 8,75 \\
\hline $\begin{array}{l}\text { Kocman, A., Fischer, L., \& Weber, G. (2018). The Employers' perspective on barriers and } \\
\text { facilitators to employment of people with intellectual disability: A differential mixed- } \\
\text { method approach. Journal of Applied Research in Intellectual Disabilities, 31(1), 120- } \\
131 \text {. }\end{array}$ & 25 & 6,25 \\
\hline $\begin{array}{l}\text { Martins, A. (2015). Using the International Classification of Functioning, Disability and } \\
\text { Health (ICF) to address facilitators and barriers to participation at work. Work, 50(4), } \\
585-593 \text {. }\end{array}$ & 25 & 3,57 \\
\hline $\begin{array}{l}\text { Mirenda, P. (2014). Revisiting the Mosaic of Supports Required for Including People with } \\
\text { Severe Intellectual or Developmental Disabilities in their Communities. Augmentative } \\
\text { and Alternative Communication, 30(1), 19-27. }\end{array}$ & 24 & 3 \\
\hline $\begin{array}{l}\text { Etherington, D., \& Ingold, J. (2012). Welfare to work and the inclusive labour market: a } \\
\text { comparative study of activation policies for disability and long-term sickness benefit } \\
\text { claimants in the UK and Denmark. Journal of European Social Policy, 22(1), 30-44. }\end{array}$ & 24 & 2,40 \\
\hline $\begin{array}{l}\text { Mank, D., Cioffi, A., \& Yovanoff, P. (1999). Impact of coworker involvement with } \\
\text { supported employees on wage and integration outcomes. Mental retardation, 37(5), } \\
\text { 383-394. }\end{array}$ & 21 & 0,91 \\
\hline $\begin{array}{l}\text { Chan, W., Smith, L. E., Hong, J., Greenberg, J. S., Lounds Taylor, J., \& Mailick, M. R. } \\
\text { (2018). Factors associated with sustained community employment among adults with } \\
\text { autism and co-occurring intellectual disability. Autism: the international journal of } \\
\text { research and practice, 22(7), 794-803. }\end{array}$ & 18 & 4,50 \\
\hline
\end{tabular}

TC: Total citations

\subsection{Country and affiliation productivity}

The most productive countries in terms of scientific publications are the United States of America with 27 documents (21.2\%), Australia with 19 (14.9\%), Canada with 16 (12.5\%) and the United Kingdom with $15(11.8 \%)$.

Figure 3. Scientific production by countries.

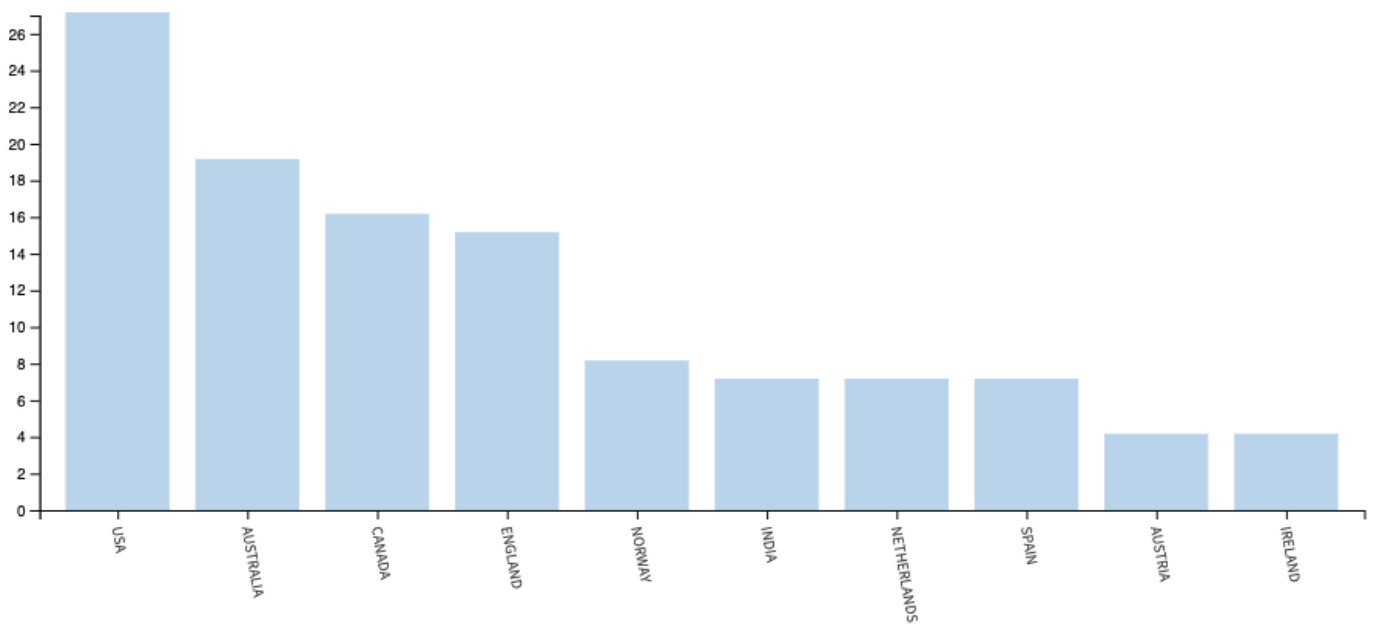

The institutions that have published the most academic papers in the WoS core collection are, coherently with productivity by country, Anglosphere universities. In particular, the most productive are McMaster University (Canada), Griffith University and La Trobe University (Australia). 
Table 3. Most relevant affiliations according to their academic productivity.

\begin{tabular}{lc}
\hline Affiliation & Documents \\
\hline McMaster University & 6 \\
\hline Griffith University & 4 \\
\hline La Trobe University & 4 \\
\hline Monash University & 4 \\
\hline University of Sydney & 4 \\
\hline University of Toronto & 4 \\
\hline Maastricht University & 3 \\
\hline McGill University & 3 \\
\hline Norwegian University of Science Technology & 3 \\
\hline University of Barcelona & 3 \\
\hline
\end{tabular}

\section{Discussion and conclusions}

The results show a growing interest in developing inclusive work environments for people with disabilities. Evidence of this is that only in 2020 almost $20 \%$ of the total articles on this subject were published and that in the last 5 years at least 5 articles were published annually. The production by author seems to indicate that the lines of research have not developed in a sustained manner over time since, for example, Ebuenyi as the most prolific author has only published 3 articles. Similarly, the most relevant publications in terms of the number of citations show that they are scarcely cited documents $(n=46$ in the best case), which could indicate that there are few research groups actively studying this question or that their productivity is scarce in terms of articles available in the WoS. The Anglo-Saxon countries such as the USA, Australia, Canada or the United Kingdom are being the most productive to date. In this sense, the production of the most productive European countries ranked among the 10 most relevant barely reaches the number of publications achieved by the USA. Therefore, research in this field should be expanded in Europe. The recommendation to expand and diversify studies on people with disabilities and employment had already been previously advised by other authors (Rey Pérez and Mateo Sanz, 2018; Ruhindwa et al., 2016; Shore et al., 2018), especially regarding research on how to develop inclusive work environments (Khayatzadeh-Mahani et al., 2019).

This study has a series of limitations that must be taken into account when interpreting its results. First, there may be relevant publications not included in the WoS core collection and that, therefore, have not been included in this analysis. Second, only papers belonging to the Social Sciences have been analyzed. Finally, the use of a limited number of terms in the search could have omitted certain articles that used other concepts. Future bibliometric investigations could try to compensate for these limitations by carrying out such analyses.

\section{Acknowledgements}

Cátedra Aguas de Alicante de Inclusión Social (University of Alicante, Spain).

\section{References}

Khayatzadeh-Mahani, A., Wittevrongel, K., Nicholas, D. B., and Zwicker, J. D. (2019). Prioritizing barriers and solutions to improve employment for persons with developmental disabilities. Disability and Rehabilitation, 42(19), 2696-2706. https://doi.org/10.1080/09638288.2019.1570356

Oliver, M. (1983). Social Work with Disabled People. Social Work with Disabled People. Macmillan Education UK. https://doi.org/10.1007/978-1-349-86058-6

Oliver, M. (2013). The social model of disability: thirty years on. Disability \& Society, 28(7), 1024-1026. https://doi.org/10.1080/09687599.2013.818773

Rey Pérez, J. L., and Mateo Sanz, L. (2018). El empleo de las personas con discapacidad: oportunidades y desafios. Madrid: Dykinson.

Ruhindwa, A., Randall, C., and Cartmel, J. (2016). Exploring the challenges experienced by people with disabilities in the employment sector in Australia: Advocating for inclusive practice-a review of literature. Journal of Social Inclusion, 7(1), 4-19. https://doi.org/10.36251/josi.99

Shore, L. M., Cleveland, J. N., and Sanchez, D. (2018). Inclusive workplaces: A review and model. Human Resource Management Review, 28(2), 176-189.https://doi.org/10.1016/j.hrmr.2017.07.003 